\begin{tabular}{|c|c|c|}
\hline & $\begin{array}{c}\text { Journal of Environmental } \\
\text { Analysis and Progress }\end{array}$ & $\begin{array}{l}\text { JBAP } \\
\text { Jounal of Environmental } \\
\text { Analysisand Progress }\end{array}$ \\
\hline 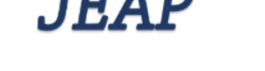 & Journal homepage: www.jeap.ufrpe.br/ & $\frac{1}{2}$ \\
\hline ISSN: 2525-815X & 10.24221/jeap.3.1.2018.1658.075-085 & \\
\hline
\end{tabular}

\title{
Impactos gerados e a gestão da bacia do rio Capibaribe-PE
}

\section{Generated impacts and the management of the Capibaribe river basin-PE}

\author{
Mariana Caroline Gomes de Lima ${ }^{a}$, Sandra Maria Ferraz de Sáa, Werônica Meira de Souza ${ }^{\mathrm{b}}$, Thais \\ Emanuelle Monteiro dos Santos ${ }^{\mathrm{c}}$ \\ a Universidade Federal de Pernambuco-UFPE, Departamento de Ciências Geográficas. Av. Prof. Moraes Rego, s/n. 1235- \\ Cidade Universitária, Recife, Pernambuco, Brasil. CEP: 50670-901. E-mail: marianalima.ambiental@gmail.com, \\ sandraferraz27@hotmail.com. \\ b Universidade Federal Rural de Pernambuco-UFRPE, Unidade Acadêmica de Garanhuns, Av. Bom Pastor, s/n - Boa \\ Vista, Garanhuns, Pernambuco, Brasil. CEP: 55292-270. E-mail: weronicameira@ gmail.com. \\ c Universidade Federal de Pernambuco-UFPE, Departamento de Biofísica e Radiobiologia. Av. Prof. Moraes Rego, s/n. \\ 1235, Cidade Universitária, Recife, Pernambuco, Brasil. CEP: 50670-901. E-mail: thaisemanulle@ hotmail.com.
}

\begin{tabular}{l}
\hline A R T I C L E I N F O \\
\hline Recebido 02 Out 2017 \\
Aceito 12 Jan 2018 \\
Publicado 29 Jan 2018
\end{tabular}

\begin{abstract}
A B S T R A C T
The spatial-temporal distribution of rainfall is an important regional feature. The knowledge of this characteristic provides guides to decisions regarding the necessary measures to minimize the damages caused by the irregularity of the rains. The high vulnerability to which the Brazilian Northeast is exposed due to the climatic instability generates a picture of the destruction of plantations, unemployment, and hunger. The study aimed to characterize and analyze climatically the precipitation behavior, its impacts and how participatory management works for the Capibaribe river basin, as support for public policies, to minimize the impacts generated. The study was conducted in the catchment area of the Capibaribe river. The pluviometric data obtained through pluviographs located in three meteorological stations were made available (APAC) for the years 1970 to 2016. It was evidenced the high temporal and spatial variability of the rains within the same basin. In which the highest rainfall indexes are found for the metropolitan region of Recife and the lowest rainfall index for the station located in Frei Miguelinho. The total precipitated blade for the station located in Recife was 86486.3, Vitória de Santo Antão was 49328.7, and Frei Miguelinho was 28566.9. The months of January to March presented the lowest precipitation rates, whereas during April to July the highest precipitation level of high intensity and short length occurs, resulting in a high risk of soil loss, environmental impacts and metropolitan region of Recife.
\end{abstract}

Keywords: Variability, environmental impacts, precipitation.

\section{R E S U M O}

A distribuição espaço-temporal das chuvas é uma característica regional importante. $\mathrm{O}$ conhecimento dessa característica orienta decisões quanto às medidas necessárias para minimizar os danos decorrentes da irregularidade das chuvas. A elevada vulnerabilidade a que está exposta o Nordeste brasileiro em decorrência da instabilidade climática gera um quadro de destruição de plantações, desemprego e fome. $\mathrm{O}$ estudo objetivou caracterizar e analisar climaticamente o comportamento das precipitações, seus impactos e como funciona a gestão participativa para a bacia hidrográfica do rio Capibaribe, servindo de suporte para políticas públicas, afim de minimizar os impactos gerados. O estudo foi conduzido na bacia hidrográfica do rio Capibaribe. Os dados pluviométricos obtidos através dos pluviógrafos localizados em três estações meteorológicas foram disponibilizados (APAC) para os anos de 1970 a 2016. Evidenciou-se a elevada variabilidade temporal e espacial das chuvas dentro de uma mesma bacia hidrográfica. Em que os maiores índices pluviométricos são encontrados para a região metropolitana do Recife e o menor índice pluviométrico para a estação localizada em Frei Miguelinho. O total da lâmina precipitada para a estação localizada no Recife foi de 86486,3 , Vitória de Santo 
Antão foi de 49328,7 e Frei Miguelinho foi de 28566,9. Os meses de janeiro a março apresentaram os menores índices de precipitação, enquanto durante os meses de abril a julho ocorreu o menor nível de precipitação de intensidade alta e curta duração, resultando em elevado risco de perda de solo, impactos ambientais e transtornos para a região metropolitana do Recife.

Palavras-Chave: Variabilidade, impactos ambientais, precipitação.

\section{Introdução}

A precipitação é definida como toda a água proveniente do vapor de água atmosférico que se deposita na superfície terrestre na forma de neblina, chuva, granizo, orvalho, geada ou neve (Pinto, 1995). Segundo Bertoni \& Tucci (1993), as principais características da precipitação são o seu total, duração e distribuição temporal e espacial, sendo que o total precipitado não tem significado se não estiver ligado a uma duração. Para Marengo et al. (2011) e Song et al. (2015), os extremos eventos de precipitação vêm sendo cada vez mais crescentes, com maior intensidade e duração, favorecendo desastres naturais como as inundações e secas severas. De acordo com Grimm (2009), na América do Sul, os principais estresses hídricos ocorrem pela variabilidade Inter-decenal e interanual da precipitação originada pela ocorrência do fenômeno El Niño, o qual é caracterizado por alterações na interação oceanoatmosfera, ocasionando mudanças no balanço hídrico.

A região semiárida do Nordeste do Brasil apresenta grande variabilidade espacial e temporal das chuvas, com precipitações mal distribuídas e concentradas em poucos meses, além da elevada evaporação da água ocasionada grande disponibilidade de energia solar, das temperaturas elevadas e da baixa umidade do ar (Assis, Souza \& Sobral, 2015). Pereira et al. (2017) identificaram no Agreste de Pernambuco que a partir da década de 1990 houve uma diminuição da frequência dos anos classificados Muito Úmidos, e aumento dos anos Muito Secos, apontando uma modificação no padrão da precipitação, onde os anos secos passaram a predominar na região.

A distribuição espaço-temporal das chuvas é uma característica regional muito importante, seja para a sociedade como à economia. Além disso, o conhecimento dessa característica pode orientar decisões quanto às medidas necessárias para minimizar os danos decorrentes da irregularidade das chuvas (Piccinini, 1993). Podemos observar que a região Nordeste do Brasil possui uma característica climática diversificada, devido a sua topografia, sua posição geográfica e, principalmente, os aspectos dinâmicos da atmosfera, que incluem os sistemas meteorológicos de micro, meso e grandes escalas, que atuam direta ou indiretamente no regime pluvial. A elevada vulnerabilidade a que está exposta o nordeste brasileiro em decorrência da instabilidade climática gera um quadro de destruição de plantações, desemprego e fome. Segundo Galvíncio et al. (2005), o problema das secas na região nordeste do Brasil está relacionado com a má distribuição das chuvas do que propriamente com a falta das mesmas, além de outros fatores, tais como uma baixa capacidade de retenção de umidade no solo e altas taxas de evaporação e evapotranspiração, que contribuem para agravar o problema.

Segundo Bertoni \& Tucci (2002), por causa da capacidade da chuva em produzir escoamento ocasionado pela baixa retenção da umidade, a chuva é o tipo de precipitação mais importante para a hidrologia, pois ela tem como consequência, a erosão hídrica. A erosão do solo é considerada um processo de origem natural com a finalidade de formação da paisagem e renovação do solo. Contudo, as atividades desenvolvidas pelo homem ao longo dos anos têm ocasionado impactos na superfície terrestre, e dessa forma, a erosão do solo acelerada por essas atividades tornase um problema nas bacias hidrográficas (Pires \& Souza, 2013). Em localidades onde a erosividade da chuva é elevada e a superfície do solo se encontra desprovida de cobertura vegetal, pode ocorrer grande degradação com consequentes perdas de solo, água, nutrientes e carbono, fatores essenciais para o crescimento e desenvolvimento das plantas, gerando também inundações (Cardoso et al., 2012). Seu conhecimento é de fundamental importância para que se tenha um planejamento adequado às inúmeras atividades humanas (Costa et al., 2015). De acordo com Albuquerque et al. (2013), o deslizamento de encostas são eventos que todos os anos causam prejuízos e mortes na Região Metropolitana do Recife (RMR), sempre relacionados com as chuvas intensas. Além dos deslizamentos, outro problema decorrente da alta precipitação pluviométrica durante o período chuvoso são os pontos de alagamentos e transbordamentos de córregos e rios na cidade do Recife.

A cidade do Recife está localizada na bacia hidrográfica do rio Capibaribe, da qual engloba as regiões Agreste, Zona da mata e litoral do Estado de Pernambuco. Na Constituição federal de 1988, foi criado capítulo específico ao meio ambiente, 
consolidando os conceitos ambientais e a propositura da criação do Sistema Nacional de Gerenciamento de Recursos Hídricos (SINGREH), considerando a água como bem público essencial à qualidade de vida, tratando da responsabilidade comum do Estado e da coletividade na defesa e contribuição da preservação do meio ambiente para as gerações presentes e futuras. A Constituição Federal vigente estabelece a dominialidade das águas, tratando como bens da União e dos Estados, porém não prevê águas de domínio municipal.

Atualmente há várias normas nacionais e estaduais que regulam a matéria da gestão de recursos hídricos e de meio ambiente no Brasil, porém merece destaque na gestão hídrica a Lei ${ }^{\circ}$ 9.433 (Brasil, 1997), que foi modelo para regulamentação da gestão hídrica dos estados brasileiros. Dentre outros aspectos, esta Lei estabeleceu a Política e o Sistema Nacional de Gerenciamento dos Recursos Hídricos com fundamentos, princípios e diretrizes da gestão das águas.

Diante das considerações apresentadas, o estudo objetivou caracterizar e analisar climaticamente o comportamento das precipitações, seus impactos e como funciona a gestão participativa para a bacia hidrográfica do rio Capibaribe, servindo de suporte para políticas públicas, afim de minimizar os impactos gerados.

\section{Material e Métodos}

Caracterização da área de estudo

$\mathrm{O}$ estudo foi conduzido na bacia hidrográfica do rio Capibaribe, que corresponde à Unidade de Planejamento hídrico UP2, com uma área de 7.454,88 $\mathrm{km}^{2}(7,58 \%$ da área do estado), localizada na porção norte-oriental do Estado de Pernambuco, entre $07^{\circ} 41^{\prime} 20^{\prime \prime}$ e $08^{\circ} 19^{\prime} 30^{\prime \prime}$ de latitude sul, e $34^{\circ} 51^{\prime} 00^{\prime}$ ' e $36^{\circ} 41^{\prime} 58^{\prime}$ ' de longitude oeste. Limita-se ao norte com o Estado da Paraíba, a bacia do rio Goiana (UP1) e grupo de bacias de pequenos rios litorâneos 1 - GL1 (UP14), ao sul com bacia do rio Ipojuca (UP3) e o grupo de bacias de pequenos rios litorâneos 2 - GL2 (UP15), a leste com o Oceano Atlântico e os grupos GL1 e GL2 e, a oeste, com o Estado da Paraíba e a bacia do rio Ipojuca.

\section{Escolha do intervalo de trinta anos para a climatologia}

Os dados pluviométricos obtidos através dos pluviógrafos localizados em três estações meteorológicas (Tabela 1) foram disponibilizados pela Agência Pernambucana de Águas e Clima (APAC). A partir dos dados armazenados nos equipamentos, as alturas de precipitação e a intensidade de chuva foram analisadas.

Tabela 1. Estações pluviométricas utilizadas e seus respectivos anos (Lima, 2017). Fonte: Autores (2017).

\section{Estações Pluviométricas}

\section{Período de coleta de dados}

Recife

Vitória de Santa Cruz

Frei Miguelinho
Janeiro de 1970 a Dezembro de 2016

Janeiro de 1970 a Dezembro de 2016

Janeiro de 1970 a Dezembro de 2016
Devido à falta de disponibilidade dos dados e séries sem falhas, apenas estas três bacias apresentaram longos períodos de dados, como destacado acima, embora a estação Recife apresente ausência de dados nos anos de 1986 a 1992.

\section{Erosividade como resultado das mudanças climáticas}

Para o estudo da erosividade foram utilizados dados de 2005 a 2011 de uma estação localizada na região metropolitana do Recife.

Para a geração dos cálculos foram consideradas apenas as chuvas individuais. A precipitação foi dividida por sua duração para obter a intensidade, em mm.h ${ }^{-1}$, conforme Foster et al. (1981). Para a determinação do índice de erosividade (EI30) foi realizada a multiplicação de dois parâmetros específicos das precipitações erosivas: energia cinética total da chuva $(\mathrm{Ec})$, em MJ mm.ha ${ }^{-1} \cdot h^{-1}$, e intensidade máxima em $30 \mathrm{~min}$ (I30), em mm h${ }^{-1}$.

De acordo com Wischmeier \& Smith (1978), expresso nas unidades do Sistema Internacional, conforme Foster et al. (1981), foi considerada a Equação 1 para o cálculo da energia cinética por milímetro de chuva.

$\mathrm{Ec}=0,119+0,0873 \log \mathrm{I},\left(\mathrm{I} \leq 76 \mathrm{~mm} \cdot \mathrm{h}^{-1}\right) \mathrm{Eq} \cdot(1 \mathrm{a})$

e Ec=0,283, $\left(\mathrm{I}>76 \mathrm{~mm} \cdot \mathrm{h}^{-1}\right)$

onde: $\mathrm{Ec}=$ Energia cinética em MJ (ha. $\mathrm{mm})^{-1} ; \mathrm{I}=$ Intensidade da chuva em $\mathrm{mm} \cdot \mathrm{h}^{-1}$.

A energia cinética por incremento de chuva foi determinada seguindo a Equação 2: 
$\mathrm{Eci}=\mathrm{EcVol}$

onde: Vol = Quantidade de chuva do incremento (lâmina precipitada em $\mathrm{mm}$ ); Eci = Energia cinética do incremento (MJ.ha ${ }^{-1}$ ).

A energia cinética total foi obtida pelo somatório da energia cinética de cada incremento, segundo a Equação 3:

$E c t=\sum$ Eci

Logo, o $\mathrm{EI}_{30}$ foi calculado pela Equação 4:

$$
\mathrm{EI}_{30}=\text { Ect I }_{30} \quad \text { Eq.(4) }
$$

As erosividades foram definidas de acordo com a classificação proposta por Carvalho et al. (2008).

\section{Resultados \\ Climatologia}

A Figura 1 mostra a distribuição do total precipitado anual para os três pluviógrafos, evidenciando a elevada variabilidade temporal e espacial das chuvas dentro de uma mesma bacia hidrográfica. Verifica-se que os maiores índices pluviométricos são encontrados para o pluviógrafo localizado na região metropolitana do Recife e o menor índice pluviométrico para a estação localizada em Frei Miguelinho. O total da lâmina precipitada para a estação localizada no Recife foi de 86486,3, em Vitória de Santo Antão foi de 49328,7 e em Frei Miguelinho foi de 28566,9.

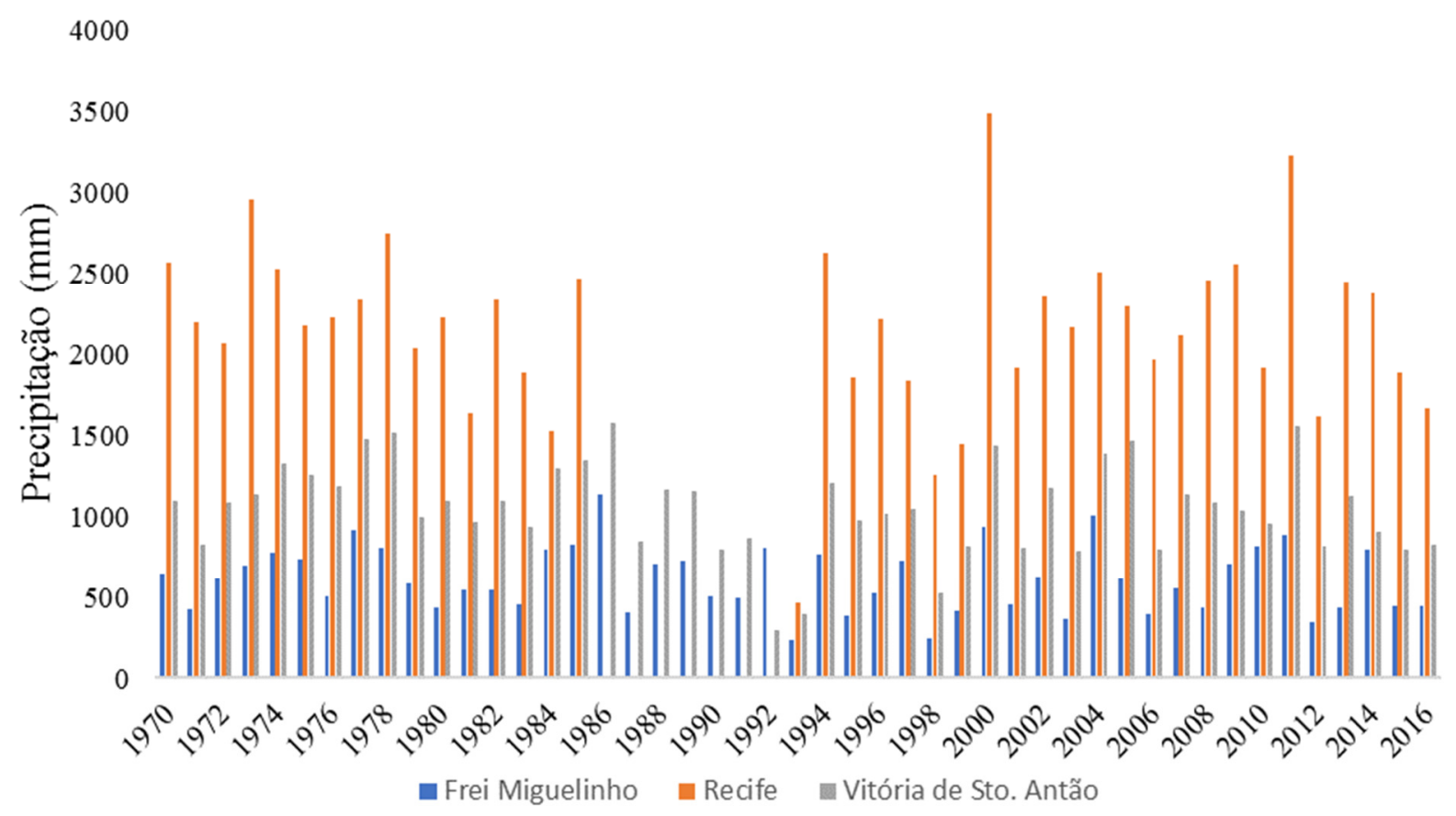

\section{Anos}

Figura 1. Distribuição anual da precipitação registrada pelos pluviógrafos localizados em Frei Miguelinho, Recife e Vitória de Santo Antão para o período de 1970 a 2016.

Evidencia-se uma elevada variabilidade temporal mensal das chuvas através da Figura 2, na qual é possível observar que durante os 12 meses do ano, os meses de janeiro a março apresentam os menores índices de precipitação, enquanto que durante os meses de abril e julho ocorre a maior lâmina precipitada de intensidade alta e de curta duração, resultando em elevado risco de perda de solo, impactos ambientais e transtornos para a região metropolitana do Recife. Vale ressaltar os meses de setembro a dezembro que apresentaram a mesma dinâmica quando se refere ao acumulado precipitado.
O acumulado das chuvas durante os quatros primeiros meses para as três estações é onde apresenta os menores índices de precipitação. $\mathrm{O}$ aumento das precipitações na transição da seca para a estação chuvosa ocorre com uma inclinação de $472,1 \mathrm{~mm}$.mês ${ }^{-1}$ de março para abril para a Frei Miguelinho ocorrendo uma estabilidade e um pico de maior intensidade em julho assim como observado para todas as áreas. Em Vitória observase uma estabilidade entre janeiro, fevereiro, seguido de abril e maio e uma variabilidade de maio a junho que representa um aumento de 1561,8 mm (mês), seguido de meses com presença 
marcante da baixa precipitação, resultando de agosto para setembro uma diminuição de 1894,7 mm (mês). Em Recife, a zona de maior transição visualmente é o mês de maio para julho com um aumento de 2166,8 mm (mês). Mas, uma característica climatológica é semelhante: A distribuição das chuvas por trimestre expressa que o acumulado de janeiro a março é basicamente igual para todas estações, abril a julho e agosto a dezembro seguem o mesmo padrão (Figura 3).

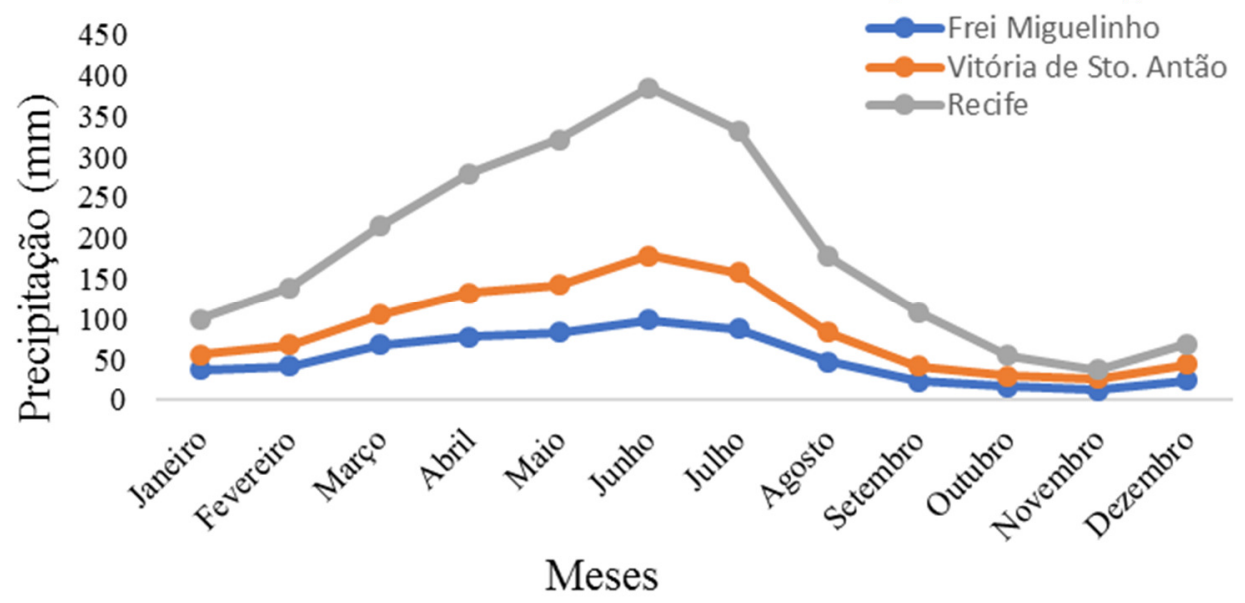

Figura 2. Variabilidade mensal das chuvas em Frei Miguelinho, Vitória de Santo Antão e Recife para o período de 1970 a 2016.
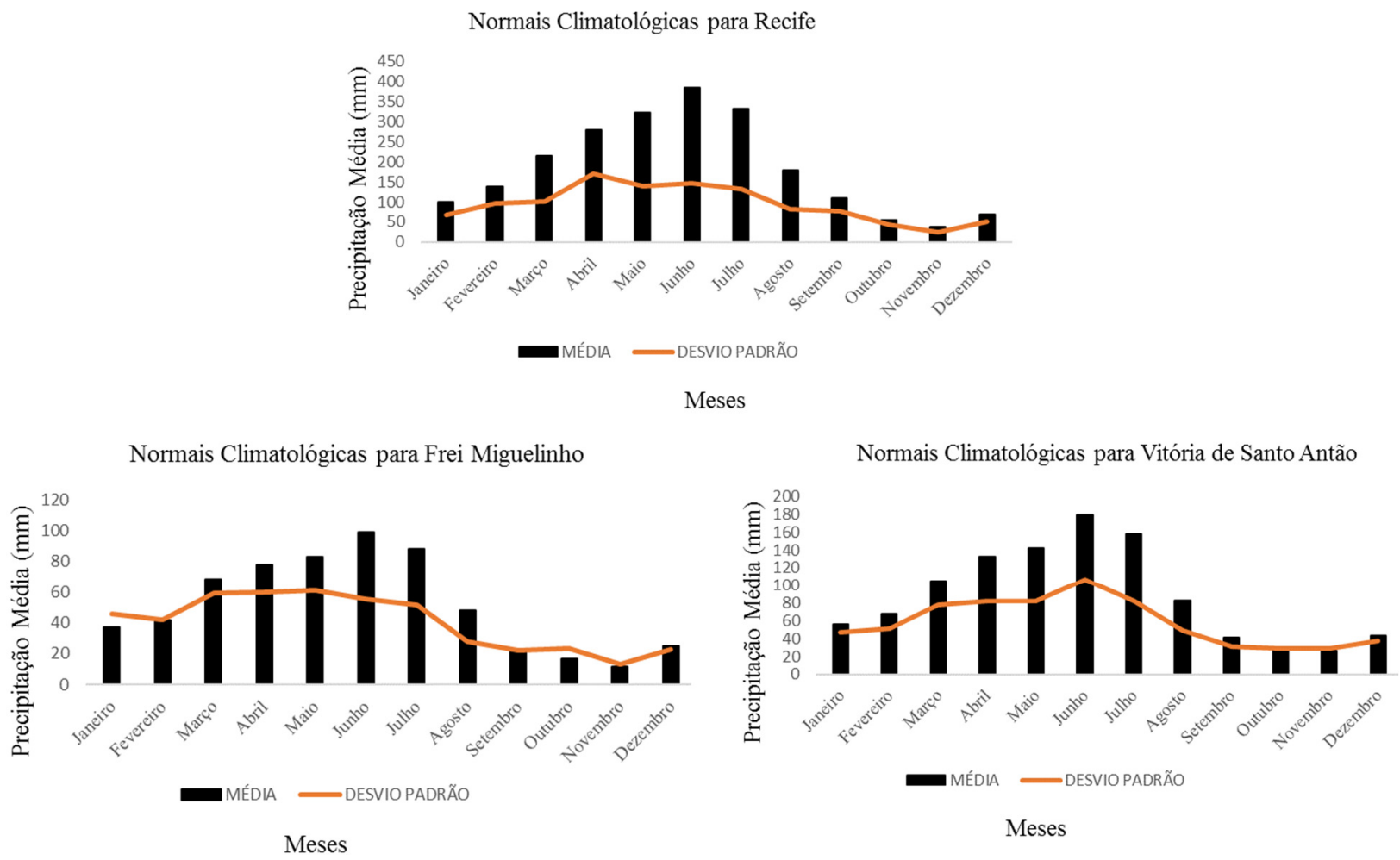

Figura 3. Normais climatológicas (média e desvio padrão, mm) das chuvas mensais, para o período 1970-2016, em Frei Miguelinho, Vitória de Santo Antão e Recife.

A variação temporal da precipitação observada durante os períodos chuvosos com suas respectivas, médias climáticas (Figura 4). Um aumento de precipitação em 1984, 1985 e 1986 evidenciou uma tendência expressiva (Figura 5). Verifica-se também um padrão de precipitação, que se mantém desde 1996, para todas as estações, com o ano de 1992 sendo marcado por uma diminuição drástica do acumulado precipitado. Vale salientar que, para a estação do Recife (Figura 4), os anos de 1986 a 1992 não apresentaram dados disponibilizados pela plataforma da APAC. 


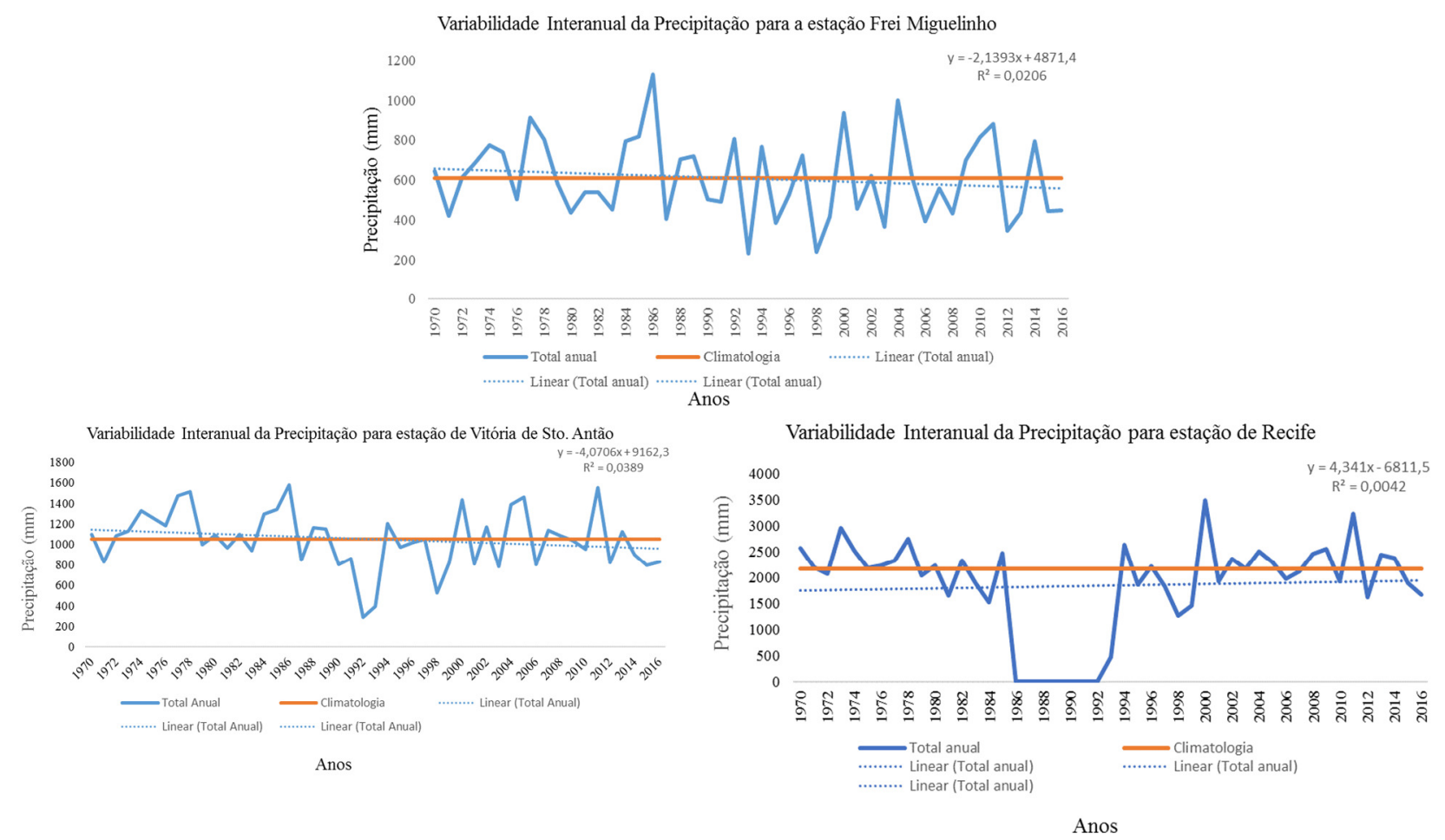

Figura 4. Variabilidade temporal da precipitação, para os períodos chuvoso para o período de 1970 a 2016, em Frei Miguelinho, Vitória de Santo Antão e Recife.

\section{Erosividade}

Observa-se abaixo os dados referentes à erosividade para a bacia do rio Capibaribe (Tabela 2). O ano de 2005 apresentou meses com ausência de chuvas acima dos $10 \mathrm{~mm}$ como encontrado também para a Bacia do Alto Ipanema, enquanto que, nos meses de julho, agosto, outubro e dezembro, a erosividade foi considerada fraca. No ano de 2006 a erosividade manteve-se fraca nos meses de fevereiro, março, julho a setembro e de novembro a dezembro, enquanto que em abril a erosividade foi considerada moderada a forte, no mês de maio erosividade foi forte e em junho observou-se uma erosividade moderada.

O ano de 2007 foi marcado por chuvas de baixa intensidade e consequentemente erosividade fraca (Tabela 2). O ano de 2008 apresentou erosividade de moderada a forte no mês de março e de moderada nos meses de abril e maio, antecedida e seguida de erosividade fraca. Para o ano de 2009, as erosividades foram classificadas como de moderada a forte, e fraca e fraca para os anos de 2010 e 2011.

Tabela 2. Erosividade $\left(\mathrm{MJ} \cdot \mathrm{mm}^{-1} \cdot \mathrm{ha}^{-1} \cdot \mathrm{h}^{-1}\right)$ mensais das chuvas para a estação localizada na Bacia do Capibaribe para os anos de 2005 a 2011.

\begin{tabular}{ccccccccccccc}
\hline Ano & Jan & Fev & Mar & Abr & Mai & Jun & Jul & Ago & Set & Out & Nov & Dez \\
\hline 2005 & 0 & 0 & 0 & 0 & 6937,78 & 9927,74 & 384,78 & 1079,88 & 0 & 39,53 & & 976,87 \\
2006 & 0 & 153,69 & 907,19 & 5407,43 & 9648,54 & 4434,60 & 534,33 & 249,77 & 24,09 & 0 & 72,73 & 103,35 \\
2007 & 0 & 279,25 & 573,84 & 2032,72 & - & - & - & - & - & - & - & - \\
2008 & 222,21 & 6,77 & 6860,62 & 2885,86 & 4855,31 & 0 & 8,48 & 0 & 0 & 116,52 & 0 & 16,63 \\
2009 & 54,90 & 2371,13 & 489,30 & 2114,7 & 6019,9 & 2328,02 & 2017,88 & 464,41 & 70,15 & 0 & 381,45 & 245,06 \\
2010 & 112,97 & 0 & 0 & 0 & 0 & 2689,31 & 214,96 & 265,10 & 7,62 & 46,90 & 1,25 & 0 \\
2011 & 0 & 0 & 0 & 1859,76 & 111,013 & 0 & 0 & 0 & 0 & 0 & 0 & 0 \\
\hline
\end{tabular}

Políticas públicas na Bacia do Rio Capibaribe

A Política Nacional de Recursos Hídricos

(Lei $\mathrm{n}^{\circ}$ 9.433/1997) foi referência para a formulação e a implantação de políticas estaduais de gerenciamento de recursos hídricos, sendo estas leis estruturalmente muito semelhantes à lei federal. Assim, a água passou a ser tratada como bem de valor econômico, e é instituída a gestão por 
bacia hidrográfica e determinada a participação da sociedade na gestão hídrica.

A gestão por bacias hidrográficas deve permitir uma visão interdisciplinar, levando-se em consideração as condições naturais, o uso do solo e as atividades humanas nelas desenvolvidas.

Tratando, especificamente, da gestão compartilhada e participativa das águas através dos Comitês de Bacias Hidrográficas - COBH observase a necessidade de garantia de princípios como a disponibilidade da água para a atual e futuras gerações, visando a disponibilização, em quantidade e qualidade adequadas para os fins pretendidos, bem como proporcionar o uso múltiplo das águas.

O sistema previsto na lei citada é formado por instâncias colegiadas, pelo órgão gestor da política estadual e órgãos executores dos programas relacionados à gestão e ao uso das águas, incluindo os Comitês de Bacias, como órgãos auxiliares da gestão, com atuação em uma bacia específica.

A Secretaria de Planejamento e Gestão de Pernambuco (SEPLAG) é o órgão responsável pela gestão da Política Estadual de Recursos Hídricos, sendo sua execução de responsabilidade da Agência Pernambucana de Águas e Clima (APAC), que tem, entre suas funções, o apoio ao funcionamento dos colegiados de bacias hidrográficas. As instâncias colegiadas tomam decisões e acompanham a execução dos programas nos seus respectivos âmbitos de atuação:

- Conselho Estadual de Recursos Hídricos $(\mathrm{CRH})$, em todo o território estadual;

- Comitês de Bacia Hidrográfica (COBHs), no âmbito de uma bacia hidrográfica. O Estado de Pernambuco possui, atualmente, sete Comitês de Bacia instituídos e homologados pelo CRH;

- Conselhos Gestores de Açude (CONSUs), na área de influência de um ou mais reservatórios. O Estado de Pernambuco possui, atualmente, 19 Conselhos Gestores instituídos e homologados pelo CRH.

O Plano Estadual de Recursos Hídricos (1998) dividiu o Estado em 29 Unidades de Planejamento (UPs), e a maior parte das grandes bacias hidrográficas pernambucanas situa-se, integralmente, dentro dos limites do Estado. De acordo com o mesmo documento, as grandes bacias hidrográficas pernambucanas possuem duas vertentes: as que escoam para o rio São Francisco formam os chamados rios interiores, além de grupos de pequenos rios interiores, as que escoam para o Oceano Atlântico, que constituem os chamados rios litorâneos, e as de pequenos rios litorâneos. A bacia do rio Capibaribe apresenta uma área de 7.454,88 $\mathrm{km}^{2}$, correspondendo a $7,58 \%$ da área total do Estado.

O COBH Capibaribe é um colegiado de caráter consultivo e deliberativo, sendo criado em 2007. Possui 45 membros, distribuído em 42 municípios, tendo como atribuições, além de atender os pressupostos da Lei das Águas (Decreto Lei $\mathrm{n}^{\circ}$ 9.433/1997), que instituiu a Política Nacional de Recursos Hídricos (PNRH) e criou o Sistema Nacional de Gerenciamento de Recursos Hídricos (SINGREH), atuar no âmbito dos comitês de bacia, estabelecer metas de racionalização de uso, acompanhar o plano de recursos hídricos da bacia hidrográfica, promover debates sobre a questão dos recursos hídricos, além de garantir a articulação e participação das entidades intervenientes.

O Comitê da Bacia Hidrográfica do rio Capibaribe (COBH Capibaribe), criado em 2007 e homologado pela Resolução CRH n ${ }^{\circ}$ 07/2007, é um órgão colegiado com competências deliberativas e consultivas vinculado, organicamente, ao sistema estadual de gestão de recursos hídricos.

De acordo com o Artigo 47 da Lei 12.984 (2005), os COBHs, deverão exercer as atribuições seguintes:

I - aprovar o estatuto social e o regimento interno do respectivo Comitê;

II - participar da elaboração e acompanhar a execução do Plano Diretor de Recursos Hídricos respectivo, assim como programas de ações para atendimento de situações críticas;

III - aprovar o Plano Diretor de Recursos Hídricos respectivo, submetendo ao $\mathrm{CRH}$ para homologação;

IV - apreciar as propostas dos programas anuais e plurianuais de aplicação de recursos financeiros em serviços e obras de interesse para o gerenciamento dos recursos hídricos na bacia, que sejam compatíveis com o Plano Diretor de Bacia Hidrográfica respectivo;

V - aprovar as propostas para o plano de utilização, conservação, proteção e recuperação dos recursos hídricos da bacia hidrográfica, promovendo a divulgação e debates;

VI - aprovar o enquadramento dos corpos de água em classe de uso preponderante e encaminhar ao CRH para homologação;

VII - promover o entendimento e relações de cooperação entre os usuários de recursos hídricos, exercendo, quando necessário, funções de arbitramento e conciliação nos casos de conflito de 
interesses, em primeira instância de decisão;

VIII - promover a divulgação e debates na região dos programas, serviços e obras a serem realizadas de interesse da comunidade, apresentando metas, benefícios, custos e riscos sociais, ambientais e financeiros;

IX - efetuar mediante delegação da autoridade outorgante, por intermédio das Agências de Bacia dos COBHs, a cobrança pelo uso de recursos hídricos;

$\mathrm{X}$ - propor ao CRH critérios e quantitativos para isenção de outorgas;

$\mathrm{XI}$ - propor ao CRH valores a serem cobrados pelo uso de recursos hídricos na bacia, na ausência de Agência de Bacias; XII - criar Câmaras Técnicas e Grupos de Trabalho; e

XIII - exercer outras ações, atividades e funções estabelecidas em lei, regulamento ou decisão do $\mathrm{CRH}$, compatíveis com a gestão de recursos hídricos.

$\mathrm{O} \mathrm{COBH}-\mathrm{Capibaribe} \mathrm{é} \mathrm{um} \mathrm{colegiado} \mathrm{de}$ caráter consultivo e deliberativo e foi criado em 23 de março de 2007. Este órgão possui 45 membros, tendo como atribuições, além de atender os pressupostos da Lei das Águas (Decreto Lei $\mathrm{n}^{\circ}$ 9.433/1997), que instituiu a Política Nacional de Recursos Hídricos (PNRH) e criou o Sistema Nacional de Gerenciamento de Recursos Hídricos (Singreh), atuar no âmbito dos comitês de bacia, estabelecer metas de racionalização de uso, acompanhar o plano de recursos hídricos da bacia hidrográfica, promover debates sobre a questão dos recursos hídricos, além de garantir a articulação e participação das entidades intervenientes.

O Comitê do Rio Capibaribe possui 45 membros, representados pelos segmentos de usuários de água, entidades civis e poderes executivos municipais, estadual e federal, com base em suas composições.

Com base em preceitos legais, a diretoria do $\mathrm{COBH}$ Capibaribe é composta por um 01 presidente, 01 vice-presidente e um secretário executivo, eleitos por maioria simples dentre seus membros, para um mandato de três anos, renovável por mais um único período. Assim, a eleição da atual Diretoria ocorreu na cidade de Recife, Estado de Pernambuco, em 26 de abril de 2017 para o mandato de 2017 a 2020 (26 de abril de 2017 a 26 de abril de 2020).

Atualmente existem as seguintes Câmaras Técnicas: a) Câmara Técnica de legislação e normas; b) Câmara Técnica de saneamento ambiental; c) Câmara Técnica de conservação dos recursos naturais; d) Câmara Técnica de enquadramento e cobrança pelo uso da água; e) Câmara Técnica de acompanhamento de planos, programas e projetos.

$\mathrm{Na}$ última assembleia geral houve uma nova eleição de membros representantes e, atualmente, as seguintes entidades compõem o COBH Capibaribe (Quadro 1).

Quadro 1. Representantes do poder público do estado de Pernambuco, usuários de recursos hídricos e entidades civis do estado de Pernambuco compõem o Comitês de Bacias Hidrográficas (COBH-Capibaribe).

\begin{tabular}{|l|l|l|}
\hline Poder Público & $\begin{array}{l}\text { Usuários de Recursos } \\
\text { Hídricos }\end{array}$ & Entidades Civis \\
\hline Prefeitura de Camaragibe & Colônia de Pescadores Z-34 & AMATUR \\
Prefeitura Municipal do Glória do & Aarragem do & Associação Fazenda Fieza de \\
Goitá & Colônia de Pescadores Z-18 & Educação Ambiental \\
Prefeitura de Lagoa de Itaenga & Lagoa do Carro & ANE - Assoc. Águas do Nordeste \\
Prefeitura de Limoeiro & Associação Rural dos & Conselho de Defesa do Meio \\
Prefeitura Paudalho & Produtores de Lagoa da Vaca & Ambiente de Brejo da Madre de \\
Prefeitura da Cidade do Recife & Associação dos Produtores & Deus \\
Prefeitura de Sta Cruz do Capibaribe & Rurais do Sítio Pinhões & Instituto de Gestão - INTG \\
Prefeitura de Vitória de Santo Antão & Usina Petribu & IFPE/Recife \\
Prefeitura da Cidade de Surubim & Usina São José & Suplente: ITCB \\
Prefeitura de São Lourenço da Mata & Compesa & UPE \\
Prefeitura Municipal de Taquaritinga & & UFPE \\
do Norte & & Sindicato das Indústrias do Material \\
Prefeitura de Vitória de Santo Antão & & Plástico de PE \\
INCRA SR03/PE & \\
I Gerência Regional de Saúde & & \\
Secretaria de Meio Ambiente e & & \\
Sustentabilidade - SEMAS & & \\
Secretaria Executiva de Recursos & \\
Hídricos DNOCS & & \\
\hline
\end{tabular}




\section{Discussão}

A variabilidade encontrada é diferente daquela observada por Fernandes (2014), ao analisar 30 anos de dados em Manaus, onde as chuvas de maiores volumes se concentram entre os meses de dezembro a maio, enquanto nos meses de junho a novembro predominam os menores volumes de chuva. Observa-se que para a Bacia do rio Capibaribe, o mês de junho foi o responsável pelo maior índice pluviométrico.

Kousky \& Chu (1978) afirmam que, considerando a região Nordeste de chuvas, pode-se encontrar, desde um clima semiárido no interior da região, com precipitação acumulada inferior a 500 mm.ano ${ }^{-1}$, até um clima chuvoso com uma alta variabilidade climática, tendo em conta o regime observado na costa leste, com um precipitado acumulado anual superior a $1500 \mathrm{~mm}$.

A variação temporal da precipitação, em relação \{a hipótese apresentada por Trenberth \& Hoar (1997), apresentou um aumento incomum na frequência e amplitude dos eventos El Niño Oscilação Sul (ENOS), nas décadas de 80 e 90, significativamente diferente dos comportamentos em séculos passados, podendo estar associada a fatores antropogênicos, resultantes do evidente aumento nas concentrações dos gases de efeito estufa nas últimas décadas. Porém, até certo ponto, estes resultados entram em conflito com aqueles encontrados por Latif et al. (1997), que objetivaram analisar, entre três teorias, qual a responsável pelas anomalias de precipitação ocorridas na década de 1990.

Os ENOS são, certamente, os responsáveis pela mais forte flutuação na escala de tempo interanual, mas a variabilidade decadal não pode ser descrita, exclusivamente, como uma modulação decadal dos ENOS, sugerindo que o modo decadal independe dos ENOS e é uma fonte para a irregularidade do fenômeno climático. Além disto, foram responsáveis pelas anomalias observadas em grande parte dos anos 90 .

Em relação às chuvas intensas que ocorrem na Região Metropolitana do Recife, elas constituem um aspecto importante do clima por ocasionar eventos geomorfológicos típicos como os deslizamentos de terra e as inundações sazonais, trazendo grandes prejuízos sociais e econômicos (Anjos, 2005; Wanderley et al., 2011). A ocorrência de processos erosivos é um fenômeno natural que acontece em todos os ecossistemas, porém, o risco de degradação do solo em regiões brasileiras é mais elevado, principalmente no Nordeste, por apresentar situações favoráveis, como chuvas de altas intensidades em um curto período de tempo.
A erosividade é, portanto, uma informação-chave em planos de recuperação de áreas degradadas. Além disso, a erosividade pode subsidiar políticas públicas, permitindo a alocação de recursos financeiros para a conservação do solo, prioritariamente para regiões mais críticas (Oliveira et al., 2011; Rodrigues et al., 2011).

$\mathrm{O}$ trabalho desenvolvido pelos Comitês de Bacias Hidrográficas tem evoluído de forma significativa, buscando minimizar os impactos gerados pela variabilidade temporal e os impactos ocasionados, mas, provavelmente, os Comitês de Bacia sejam o maior desafio na construção da nova institucionalidade proposta pelas Leis que regulam a matéria. Atuando de forma administrativa na gestão das águas, são instâncias diferenciadas, pois incluem atores que não estão vinculados aos interesses dos governos e sua organização deve estar vinculada tanto à sua agenda objetiva, com relação à gestão de conflitos potenciais e futuros dos usos das águas, quanto à sua capacidade de gerar os recursos necessários para sua sustentação.

\section{Conclusão}

Em uma mesma bacia hidrográfica ocorre uma elevada variabilidade temporal e espacial das chuvas.

O monitoramento dos índices pluviométricos minimizam os impactos ambientais, sociais e econômicos impulsionados pelas altas intensidades pluviométricas através de planos de manejo.

A gestão setorizada por bacia hidrográfica permite uma visão interdisciplinar que considera as condições naturais, o uso do solo e as atividades humanas desenvolvidas, considerando, especificamente, a gestão compartilhada e participativa das águas através dos Comitês de Bacias Hidrográficas.

\section{Agradecimentos}

À Agência Pernambucana de Águas e Clima (APAC) pela disponibilidade dos dados de chuva. À Universidade Federal de Pernambuco, através do Programa de Pós-Graduação em Desenvolvimento e Meio Ambiente (PRODEMA). Agradecimentos

À Fundação de Amparo a Ciência e Tecnologia de Pernambuco (FACEPE) por meio do Projeto de Pesquisa APQ-0762-1.07/15 ao Ministério da Ciência, Tecnologia e Inovação (MCTI), por intermédio do Conselho Nacional de Desenvolvimento Científico e Tecnológico (CNPq), e a Agência Nacional de Águas (ANA), por meio do edital MCTI/CNPq/ANA n.23/2015. 


\section{Referências}

ANJOS, R. J. 2005. Aguaceiros em Recife-PE: uma climatologia de 36 anos. Recife: INMET.

ALBUQUERQUE, R. T. B. DE; DANTAS, C. E. DE O.; ARAÚJO, V. E. L. T. L. 2013. Distribuição Temporal das Precipitações no Município do Recife. Revista Brasileira de Geografia Física, v. 06, n. 02, p. 245-252.

ASSIS, J. M. O.; SOUZA, W. M.; SOBRAL, M. C. M. 2015. Climate analysis of the rainfall in the lower-middle stretch of the São Francisco river basin based on the rain anomaly index. Revista Brasileira de Ciências Ambientais, v. 2, p. 188-202.

BERTONI, J.C.; TUCCI, C.E. 1993. Precipitação. In: TUCCI, C.E. (Ed.). Hidrologia: ciência e aplicação. Porto Alegre: Editora da Universidade, cap. 5, pp. 177-241.

BERTONI, J. C.; TUCCI, C. E. M. 2002, Precipitação. In: TUCCI, C. E. M. (Org.). Hidrologia: ciência e aplicação. 3.ed. Porto Alegre: Ed. Universidade/UFRGS: ABRH, 943p.

BRASIL. Lei no 9.433, de 08 de janeiro de 1997. Institui a Política Nacional de Recursos Hídricos, cria o Sistema Nacional de Recursos Hídricos, regulamenta o inciso XIX do art. 21 da Constituição Federal e altera $o$ art. $1^{\circ}$ da Lei $n^{\circ}$ 8.001 , de 13 de março de 1990, que modificou a Lei $\mathrm{n}^{\circ}$ 7.990, de 28 de dezembro de 1989. Disponível em: http://www2.camara.leg.br/legin/fed/lei/1997/lei9433-8-janeiro-1997-374778-normaatualizadapl.pdf. Acesso em: 27 maio 2017.

CARVALHO, N. O. 2008. Hidrossedimentologia prática. 2.ed. Rio de Janeiro: Interciência, 599p.

CARDOSO, D. P.; SILVA, M. L. N.; CARVALHO, G. J.; FREITAS, D. A. F.; AVANCI, J. C. 2012. Plantas de cobertura no controle das perdas de solo, água e nutrientes por erosão hídrica. Revista de Engenharia Agrícola e Ambiental, v. 16, n. 6, p. 632-638.

COSTA M. S. et al. 2015.Tendências observadas em extremos de precipitação sobre a região Semiárida do Nordeste do Brasil. Revista Brasileira de Geografia Física, v. 08 n. 05 p. 13211334.

FERNANDES, M. J. S. 2014. Revista Geonorte, Edição Especial 4, v. 10, n. 1, p. 46-49.
FOSTER, G. R.; MC COOL, D. K.; RENARD, K. G.; MOLDENHAUER, W. C. 1981. Conversion of the universal soil loss equation to SI metric units. Journal of Soil Water Conservation, v. 36, p. 355359.

GALVÍNCIO, J. D. et al. 2005 Aspectos climáticos da captação de água de chuva no estado de Pernambuco. Revista de Geografia (Recife), Recife, v. 22, n. 2, p. 100-116.

GRIMM, A. M.; TEDESCHI, R. G. 2009. ENSO and extreme rainfall events in South America. Journal of Climate, v. 22, p. 1589-1609.

KOUSKY, V. E.; CHU, P. S. 1978. Fluctuations in annual rainfall for Northeast Brazil. Journal of Meteorological Society of Japan, v. 56, p. 457-465.

LATIF, M.; KLEEMAN, R.; ECKERT, C. 1997. Greenhouse warming, decadal variability, or El Niño? An attempt to understand the anomalous 1990s. Journal of Climate, v. 10, n. 9, p. 22212239.

MARENGO, J. A. TOMASELLA, J.; ALVES, L. M.; SOARES, W. R.; RODRIGUEZ, D. A. 2011. The drought of 2010 in the context of historical droughts in the Amazon region. Geophysical Research Letters, v. 38, L12703, p. 1-5.

OLIVEIRA, P. T. S.; ALVES SOBRINHO, T.; RODRIGUES, D. B. B.; PANACHUKI, E. 2011. Erosion risk mapping applied to environmental zoning. Water Resource Management, v. 25, p. 1021-36.

PEREIRA, M. L. T.; SOARESA, M. P. A., SILVA, E. A.; MONTENEGRO, A. A. A.; SOUZA, W. M. 2017. Variabilidade climática no Agreste de Pernambuco e os desastres decorrentes dos extremos climáticos. Journal of Environmental Analysis and Progress, v. 02, p. 394-402.

PERNAMBUCO. Lei $\mathrm{n}^{\circ} 12.984$, de 30 de dezembro de 2005. Dispõe sobre a Política Estadual de Recursos Hídricos e o Sistema Integrado de Gerenciamento de Recursos Hídricos, e dá outras providências. Disponível em: http://legis.alepe.pe.gov.br/arquivoTexto.aspx?tip onorma $=1 \&$ numero $=12984 \&$ complemento $=0 \&$ an o=2005\&tipo $=\& u r l=$. Acesso em: 27 maio 2017 .

PERNAMBUCO. Lei $\mathrm{n}^{\circ} 15.452$, de 15 de janeiro de 2015. (Vide a Lei $\mathrm{n}^{\circ} 15.461$, de 9 de março de 2015). Dispõe sobre a estrutura e o funcionamento do Poder Executivo. Disponível em: http://legis.alepe.pe.gov.br/arquivoTexto.aspx?tip 
onorma $=1 \&$ numero $=15452 \&$ complemento $=0 \&$ an o=2015\&tipo $=\& u r l=$. Acesso em: 27 maio 2017.

PERNAMBUCO. Lei no 16.069 , de 15 de junho de 2017. Altera a Lei $\mathrm{n}^{\circ} 15.452$, de 15 de janeiro de 2015, que dispõe sobre a estrutura e o funcionamento do Poder Executivo. Disponível em:

http://legis.alepe.pe.gov.br/arquivoTexto.aspx?tip onorma $=1 \&$ numero $=16069 \&$ complemento $=0 \&$ an $\mathrm{o}=2017 \&$ tipo $=\&$ url $=$. Acesso em: 18 jun 2017.

PROJETEC-BRLI. 2010. Plano hidroambiental da bacia hidrográfica do rio Capibaribe. Recife. 389p. (Tomo I - diagnóstico hidroambiental, vol. 01/03, Projetos Técnicos).

PICCININI, M. R. D. 1993. Distribuições de probabilidade de precipitação de intensidade máxima para Piracicaba, SP. 81f. Dissertação (Mestrado em Estatística e Experimentação Agronômica). Escola Superior de Agricultura
"Luiz de Queiroz", Universidade de São Paulo, Piracicaba.

SONG et al. 2015. Recent changes in extreme precipitation and drought over the Songhua River Basin, China, during 1960-2013. Atmospheric Research, v. 157, p. 137-152.

TRENBERTH, K. E.; HOAR, T. J. 1997. El Niño and climate change. Geophysical Research Letters, v. 24 , n. 23 , p. $3057-3060$.

WANDERLEY, L. S. A. 2011. Vulnerabilidade à ocorrência de eventos extremos de precipitação na região metropolitana de recife, Pernambuco. Anais IV Simpósio Internacional de Climatologia, João Pessoa, PB, Brasil.

WISCHMEIER, W. H.; SMITH, D. D. 1978. Predicting rainfall erosion losses: A guide to conservation planning. Washington: US Department of Agriculture, Agriculture Handbook, n. 537 , p. 58. 